\title{
BMJ Open Carotid artery stiffness in rural adult Chinese: a cross-sectional analysis of the community-based China stroke cohort study
}

\author{
Yao Wei (1) , ${ }^{1}$ Ming Wang, ${ }^{1}$ Yang Gui, ${ }^{1}$ Xuemei Piao, ${ }^{1}$ Conghui Sun, ${ }^{1}$ Xuehe Zhang, ${ }^{1}$ \\ Feifei Zhai, ${ }^{2}$ Yicheng Zhu, ${ }^{2}$ Liying Cui, ${ }^{2}$ Shuyang Zhang, ${ }^{3}$ Qing Dai, ${ }^{1}$ Meng Yang ${ }^{1}$
}

To cite: Wei Y, Wang M, Gui Y, et al. Carotid artery stiffness in rural adult Chinese: a cross-sectional analysis of the community-based China stroke cohort study. BMJ Open 2020;10:e036398. doi:10.1136/ bmjopen-2019-036398

- Prepublication history for this paper is available online To view these files, please visit the journal online (http://dx.doi. org/10.1136/bmjopen-2019036398).

Received 13 December 2019 Revised 10 September 2020 Accepted 22 September 2020

Check for updates

(C) Author(s) (or their employer(s)) 2020. Re-use permitted under CC BY-NC. No commercial re-use. See rights and permissions. Published by BMJ.

${ }^{1}$ Ultrasound, Peking Union Medical College Hospital, Beijing, China

${ }^{2}$ Neurology, Peking Union Medical College Hospital, Beijing, China

${ }^{3}$ Cardiology, Peking Union Medical College Hospital, Beijing, China

Correspondence to

Dr Meng Yang;

amengameng@hotmail.com

\section{ABSTRACT}

Objectives To derive normative carotid artery stiffness data in rural adult Chinese population-based study of ultrasound measurements of carotid elasticity by using quality arterial stiffness (QAS), and to assess the changes of relevant parameters in Chinese adults 40 years of age and older.

Design A China stroke cohort study (total number: 1586) in the northern countryside were carried out between June 2013 and April 2016, designed to investigate the risk factors of cardiovascular and age-related diseases.

Setting The present study was a cross-sectional analysis of an ongoing community-based Shunyi cohort study in China.

Participants A total of 583 participants (227 men and 356 women; aged $40-80$ years) with ultrasound carotid QAS examination were retrieved from the study to analyse.

Primary and secondary outcome measures Arterial stiffness parameters included diastolic diameter (Dd), pulse wave velocity (PWV), stiffness indices $\alpha$ and $\beta$ were calculated by QAS. Other clinical indicators included physical measurements, medical histories and blood biochemical test.

Results In the entire study sample, mean Dd was $7.93 \pm 0.88 \mathrm{~mm}$, mean PWV was $9.4 \pm 2.4 \mathrm{~m} / \mathrm{s}$, mean $\alpha$ was $7.65 \pm 5.13$ and mean $\beta$ was $15.53 \pm 10.29$. PWV was significant higher in participants with hypertension $(9.9 \mathrm{~m} / \mathrm{s}$ vs $9.2 \mathrm{~m} / \mathrm{s}$ in those without, $p=0.002)$, and with diabetes $(10.3 \mathrm{~m} / \mathrm{s}$ vs $9.2 \mathrm{~m} / \mathrm{s}$ in those without, $p=0.003$ ). PWV were significantly higher in participants with $\mathrm{HbA1c}$ at $5.8 \%-6.4 \%$ versus $<5.8 \%$, but no difference was found between subjects with glycohaemoglobin ( $\mathrm{HbA1c})$ at $5.8 \%-6.4 \%$ versus $>6.4 \%(p=0.005, p=0.955$, respectively). Age increase by every 10 years was associated with Dd increased by $0.27 \mathrm{~mm}$, PWV increased by $1.2 \mathrm{~m} / \mathrm{s}$, $\alpha$ increased by 1.34 and $\beta$ increased by 2.71. Systolic blood pressure (SBP) increase by every 10 $\mathrm{mm} \mathrm{Hg}$ was associated with Dd increased by $0.15 \mathrm{~mm}$, PWV increased by $0.35 \mathrm{~m} / \mathrm{s}$, $\alpha$ increased by 0.13 and $\beta$ increased by 0.15 .

Conclusion Among the participants older than 40 years, stiffness of the carotid artery had differences between hypertension and non-hypertension adults, as well as between diabetes and non-diabetes adults. Stiffness of the carotid artery also have differences between adults with $\mathrm{HbA} 1 \mathrm{c}$ at $5.8 \%-6.4 \%$ versus $<5.8 \%$. Stiffness of the
Strengths and limitations of this study

- The ultrasound automated quality arterial stiffness (QAS) technique, which possesses favourable reliability and feasibility, can be used for assessing local arterial elasticity non-invasively and comprehensively.

- The ultrasound automated QAS technique, which was economical and practical, can be used for large sample screening.

- The ultrasound automated QAS was limited by some special conditions such as arrhythmia, carotid multiple atherosclerosis plaques, carotid with excessive bending, carotid with excessive pulsatility and excessive superficial carotid.

carotid artery increases with increasing age and increasing SBP at a range from 40 and up.

\section{INTRODUCTION}

The stiffening of arteries is the most important cause for the increase in both systolic and pulse pressures as well as the decrease in diastolic blood pressure (DBP) in people 40 years of age and older. These changes lead to cardiovascular complications, such as left ventricular hypertrophy, aneurysm formation and rupture. Arterial stiffness is an independent predictor of cardiovascular, cerebrovascular and all-cause mortality. ${ }^{12}$ Hence, non-invasive determination of arterial stiffness during routine ultrasound examination of the carotid arteries is a powerful clinical tool in cardiovascular disease (CVD) prevention. Carotid ultrasound is one of the several imaging modalities that allow non-invasive assessment of vascular anatomy and function. ${ }^{34}$ Recently, high resolution ultrasound acquisitions based on radio frequency (RF) signal have given the opportunity to assess precisely local arterial wall properties, ${ }^{5}$ which may be performed by using automatic quality 
arterial stiffness (QAS). QAS provides a list of standard arterial stiffness parameters including diastolic diameter (Dd), pulse wave velocity (PWV), the stiffness indices $\alpha$ and $\beta$, which are calculated by combining the measured values with the brachial blood pressure measured externally through an automated system or standard cuff. In the present study, we used QAS with the aim of determining carotid arterial stiffness in a population defined by age and blood pressure in the northern countryside of China.

\section{METHODS}

\section{Study population}

The present study was a cross-sectional analysis of an ongoing community-based Shunyi cohort study in China, designed to investigate the risk factors of cardiovascular and age-related diseases. The study design has been described elsewhere. ${ }^{6}$ Briefly, 1586 inhabitants were recruited between June 2013 and April 2016. In each village, temporary assessment clinics were set up in residential centres. All participants attending the study underwent an interview and had their physical measurements recorded. The participants also provided blood and urine samples and underwent carotid ultrasound. In our study, the exclusion criteria included adults under
40 years old, stroke, cerebral haemorrhage, myocardial infarction, arrhythmia, carotid multiple atherosclerosis plaques, carotid with excessive bending, carotid with excessive pulsatility and excessive superficial carotid. People who could not obtain satisfactory QAS waveforms in 5 min were also excluded. Finally, among the inhabitants, 583 participants (227 men and 356 women; aged 40-80 years) completed carotid artery stiffness examination (figure 1).

\section{Carotid QAS}

Participants were in a supine position. Common carotid arterial ultrasound parameters were measured using a Mylab Twice Color Doppler ultrasound diagnostic system (Esaote, Genova, Italy) using a linear 5-13 MHz transducer (LA523) with built in a previously validated RF-based QAS module. This module used a complex algorithm that could process all data coming from the region of interest (ROI) as RF signals offline. It can be used for quantitative evaluation of the properties of the vessel wall.

The left common carotid artery (LCCA), carotid bulb and portions of the internal carotid arteries were scanned twice by one trained sonographer for each participant. The reproducibility of QAS technique varied in different indicators and methods has been discussed elsewhere. ${ }^{7}$ The ROI was a $15 \mathrm{~mm}$ long segment, about $10 \mathrm{~mm}$ proximal

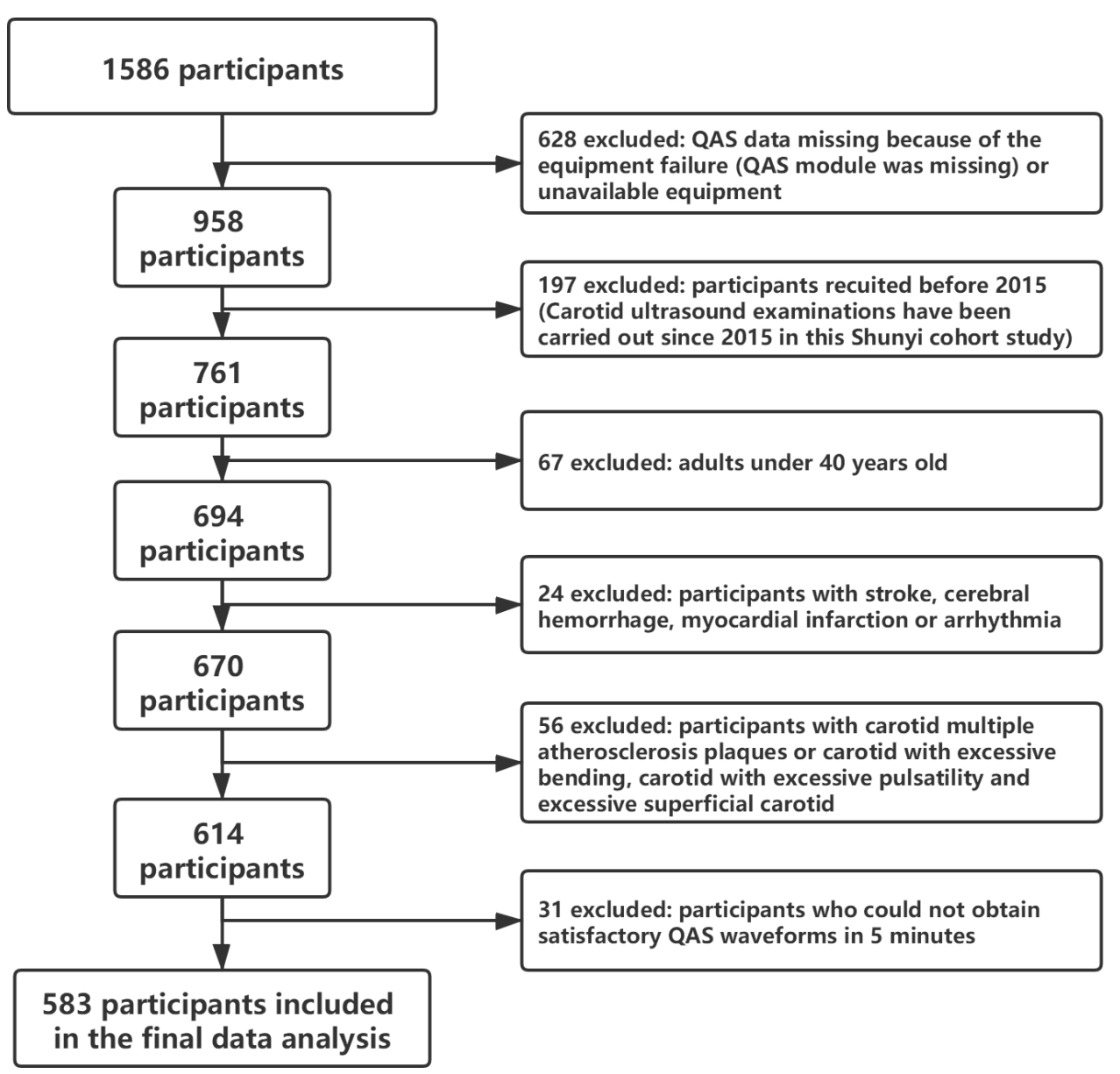

Figure 1 Participant selection flowchart. QAS, quality arterial stiffness. 


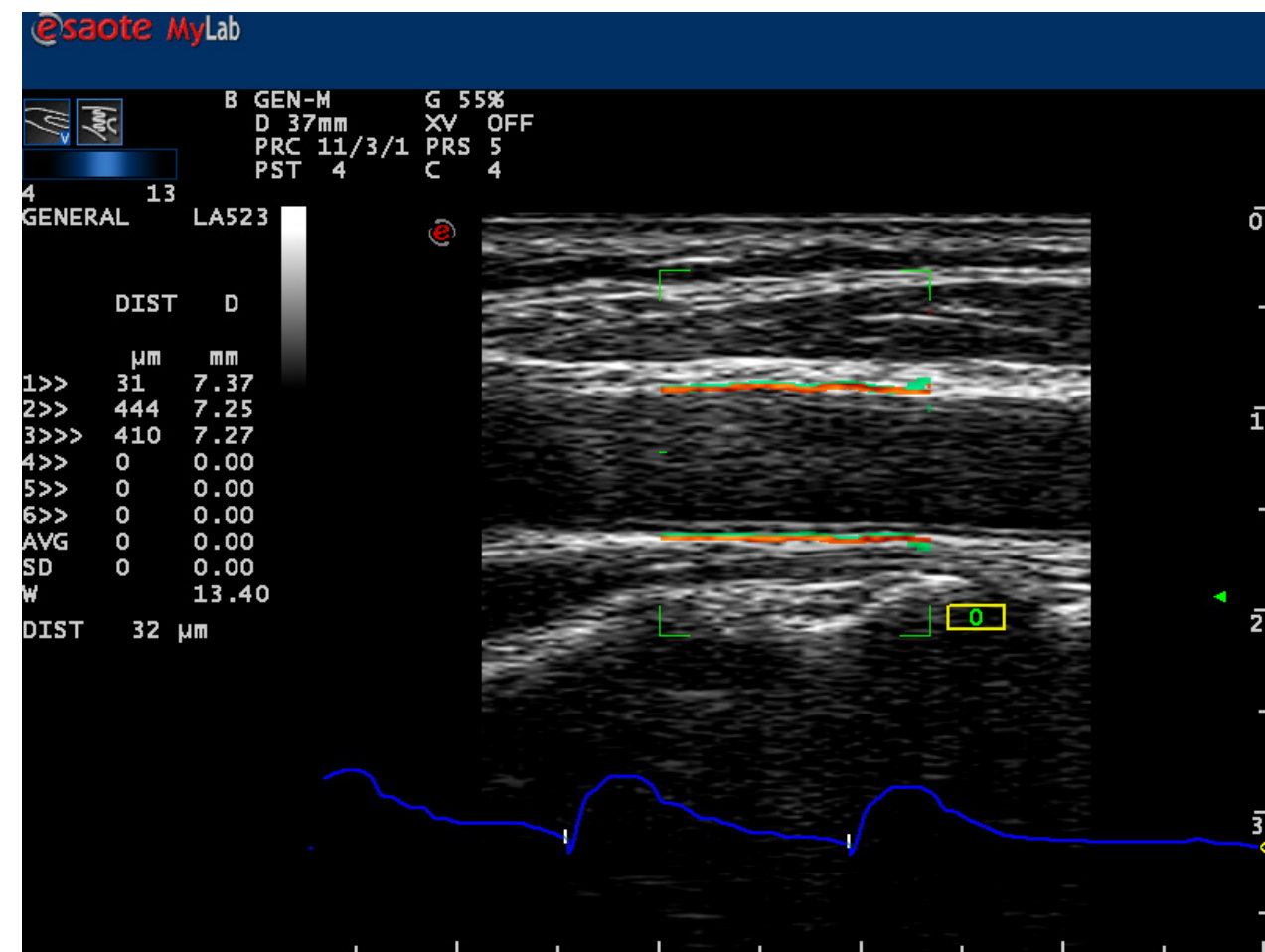

Figure 2 Quality arterial stiffness analysis of the common carotid artery. The red line represents the radio frequency (RF) signal tracking the leading edge of the lumen intima; the green line represents the RF signal tracking the leading edge of medial adventitial interface.

to the carotid bifurcation, where is free of plaque. QAS measurements automatically measured the changes in the arterial diameter between the systolic and diastolic phases on the LCCA segments. A RF signal tracked the vascular wall, while another signal tracked the motion of the vascular wall for at least six cardiac cycles and the mean and SD values were calculated automatically. The SD value was controlled with a cut-off value 15 (figure 2). The QAS data analysis software also calculated the Dd $(\mathrm{mm})$, the PWV $(\mathrm{m} / \mathrm{s})$ and the stiffness indices $\alpha$ and $\beta$ (figure 3). One-point carotid PWV was calculated applying the Bramwell-Hill equation ${ }^{8}: \quad \mathrm{PWv}=\frac{1}{\sqrt{\rho \cdot \mathrm{DC}}}=\sqrt{\frac{\mathrm{Dd}^{2} \cdot \Delta p}{\rho \cdot\left(2 \cdot \mathrm{Dd} \cdot \Delta D+\Delta D^{2}\right)}}$, where $\mathrm{Dd}$ : diastolic diameter, $\Delta \mathrm{D}$ : change in diameter in systole, DC: distensibility coefficient, $\Delta \mathrm{p}$ : local pulse pressure and $\rho$ : blood density. PWV is a functional parameter directly affected by arterial wall stiffness. The stiffness index $\alpha$ was expressed as: $\ln \left(\frac{\mathrm{Ps}}{\mathrm{Pd}}\right) \times \mathrm{Ad} /(\mathrm{As}-\mathrm{Ad})$, where Ps and Pd are carotid systolic and DBP, respectively; As: systolic area and Ad: diastolic area. The stiffness index $\beta$ was expressed as: $\ln \left(\frac{\mathrm{Ps}}{\mathrm{Pd}}\right) \times \mathrm{Dd} / \Delta \mathrm{D}$.

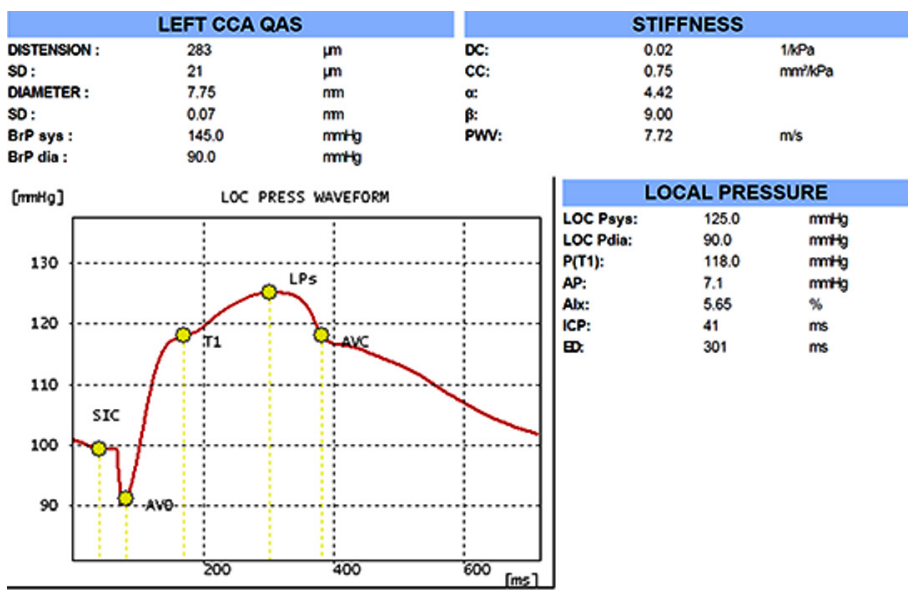

Figure 3 Quality arterial stiffness analysis of the common carotid artery. The stiffness value was calculated automatically for six cardiac cycles. 


\section{Statistical methods}

All data are expressed as the mean $\pm \mathrm{SD}$ for continuous variables. General linear regression analysis, independent sample t-test and analysis of variance (ANOVA, Bonferroni t-test) were used to assess the correlations among all the parameters. The results were considered significant at $\mathrm{p}<0.05$. The statistical software package SPSS V.19.0 (IBM Corporation) was used for all data analyses.

\section{Patient and public involvement}

This research was done without patient involvement. Patients were not invited to comment on the study design and were not consulted to develop patient relevant outcomes or interpret the results. Patients were not invited to contribute to the writing or editing of this document for readability or accuracy.

\section{RESULTS}

\section{Population characteristics}

Among the 583 participants with carotid ultrasound measurements, the mean $\pm \mathrm{SD}$ age at measurement was $54.6 \pm 7.8$ years, $38.9 \%$ were men, and $61.1 \%$ were women. The mean systolic blood pressure (SBP) was $132 \pm 20 \mathrm{~mm}$ $\mathrm{Hg}$, the mean DBP was $79 \pm 11 \mathrm{~mm} \mathrm{Hg}$, the mean body mass index (BMI) was $26.4 \pm 3.8$, the mean blood glucose (Glu) was $6.0 \pm 1.7 \mathrm{mmol} / \mathrm{L}$, the mean glycohemoglobin (HbAlc) was $5.8 \% \pm 0.9 \%$, the mean total aldehyde was $4.91 \pm 0.94 \mathrm{mmol} / \mathrm{L}$, the mean low density lipoprotein cholesterol was $2.91 \pm 0.77 \mathrm{mmol} / \mathrm{L}$ and the mean triglyceride was $1.84 \pm 2.38 \mathrm{mmol} / \mathrm{L}$ (table 1). Overall, $33.3 \%$ of the participants had hypertension, and $17.2 \%$ had diabetes (table 1 ).

\section{Quality assurance of carotid measurements}

Among the 583 participants with carotid ultrasound measurements, arterial stiffness parameters calculated by QAS were listed in table 2. The values of Dd, PWV, $\alpha$ and $\beta$ were not different between men and women $(p=0.304$, $\mathrm{p}=0.087, \mathrm{p}=0.182, \mathrm{p}=0.177$, respectively, table 2 ).

\section{Comparison of arterial stiffness parameters in medical histories and $\mathrm{HbA1C}$}

The results of the QAS analysis in table 3 show that PWV was much higher in participants with hypertension $(\mathrm{p}=0.002)$. The $\mathrm{Dd}$, stiffness indices $\alpha$ and $\beta$ were also slightly higher in participants with hypertension, but they were not significantly different $(\mathrm{p}=0.105, \mathrm{p}=0.623$, $\mathrm{p}=0.615$, respectively). The PWV, stiffness indices $\alpha$ and $\beta$ were much higher in participants with diabetes $(\mathrm{p}=0.003$, $\mathrm{p}=0.029, \mathrm{p}=0.030$, respectively). The $\mathrm{Dd}$ was slightly higher in participants with diabetes, but no significant difference was found $(\mathrm{p}=0.160)$.

The HbA1c concentration represents a continuum: values $<5.8 \%$ indicate a lower risk for diabetes, whereas those $>6.4 \%$ indicate the presence of diabetes. HbAlc concentrations of $5.8 \%-6.4 \%$ are associated with an increasing risk of diabetes. ${ }^{9}$ Considering the medical
Table 1 Distribution of demographic information, medical history and physical measurements in the study

\begin{tabular}{|c|c|}
\hline All participants $(n=583)$ & Mean \pm SD or $n(\%)$ \\
\hline \multicolumn{2}{|c|}{ Demographic/medical history } \\
\hline Age, years & $54.6 \pm 7.8$ \\
\hline Sex, \% male & $227(38.9)$ \\
\hline Hypertension, n (\%) & 194 (33.3) \\
\hline Prior diabetes, $\mathrm{n}(\%)$ & $100(17.2)$ \\
\hline \multicolumn{2}{|l|}{ Physical measurements } \\
\hline Height, $\mathrm{cm}$ & $159.6 \pm 8.0$ \\
\hline Weight, kg & $67.2 \pm 11.3$ \\
\hline $\mathrm{BMI}, \mathrm{kg} / \mathrm{m}^{2}$ & $26.4 \pm 3.8$ \\
\hline SBP, mm Hg & $132 \pm 20$ \\
\hline DBP, $\mathrm{mm} \mathrm{Hg}$ & $79 \pm 11$ \\
\hline \multicolumn{2}{|l|}{ Blood tests } \\
\hline Glu, mmol/L & $6.0 \pm 1.7$ \\
\hline $\mathrm{HbA} 1 \mathrm{c}, \%$ & $5.8 \pm 0.9$ \\
\hline $\mathrm{TCHO}, \mathrm{mmol} / \mathrm{L}$ & $4.91 \pm 0.94$ \\
\hline LDL-C, $\mathrm{mmol} / \mathrm{L}$ & $2.91 \pm 0.77$ \\
\hline $\mathrm{TG}, \mathrm{mmol} / \mathrm{L}$ & $1.84 \pm 2.38$ \\
\hline
\end{tabular}

BMI, body mass index; DBP, diastolic blood pressure; Glu, glucose; HbA1c, glycohemoglobin; LDL-C, low density lipoprotein cholesterol; SBP, systolic blood pressure; $\mathrm{TCHO}$, total aldehyde; TG, triglyceride.

treatment influence to the participants with prior diabetes, we divided all participants into lower risk for diabetes (without diabetes), increasing risk of diabetes (without diabetes) and prior diabetes. The results of the QAS analysis in table 4 show that both of PWV and Dd increased with the lower, increasing risk of diabetes and diabetes group. PWV had a significant difference between lower risk and increasing risk of diabetes $(p=0.005)$. But there was no significant difference between increasing risk of diabetes and diabetes group $(\mathrm{p}=0.955)$. Dd had no significant difference among lower risk, increasing risk of diabetes and diabetes group $(\mathrm{p}=0.363, \mathrm{p}=0.810, \mathrm{p}=0.908$, respectively).

\section{Associations with all the parameters}

Age, SBP and HbAlc had a significant linear correlation with the $\operatorname{Dd}(\mathrm{p}<0.001, \mathrm{p}<0.001, \mathrm{p}=0.010$, respectively $)$. Age, SBP had a significant linear correlation with the PWV ( $\mathrm{p}<0.001, \mathrm{p}=0.012$, respectively).

\section{Associations with age and SBP}

In the entire study sample, mean Dd was $7.93 \pm 0.88 \mathrm{~mm}$, mean PWV was $9.4 \pm 2.4 \mathrm{~m} / \mathrm{s}$, mean $\alpha$ was $7.65 \pm 5.13$ and mean $\beta$ was $15.53 \pm 10.29$ (table 2 ).

Age increase by every 10 years was associated with Dd increased by $0.27 \mathrm{~mm}$, PWV increased by $1.2 \mathrm{~m} / \mathrm{s}$, $\alpha$ increased by 1.34 and $\beta$ increased by 2.71 (table 2 , figure 4). 
Table 2 Common carotid arterial characteristics of participants and distribution of mean \pm SD values of arterial stiffness parameters by sex, age and SBP

\begin{tabular}{|c|c|c|c|c|c|}
\hline & $\mathbf{N}$ & $\begin{array}{l}\text { Dd, } \mathrm{mm} \\
\text { Mean } \pm \text { SD }\end{array}$ & $\begin{array}{l}\text { PWV, m/s } \\
\text { Mean } \pm S D\end{array}$ & $\begin{array}{l}\alpha \\
\text { Mean } \pm \text { SD }\end{array}$ & $\begin{array}{l}\beta \\
\text { Mean } \pm \text { SD }\end{array}$ \\
\hline All & 583 & $7.93 \pm 0.88$ & $9.4 \pm 2.4$ & $7.65 \pm 5.13$ & $15.53 \pm 10.29$ \\
\hline \multicolumn{6}{|l|}{ Sex } \\
\hline Male & 227 & $8.00 \pm 0.88$ & $9.2 \pm 2.6$ & $7.30 \pm 6.40$ & $14.81 \pm 12.84$ \\
\hline \multirow[t]{2}{*}{ Female } & 356 & $7.90 \pm 0.88$ & $9.6 \pm 2.3$ & $7.88 \pm 4.11$ & $16.00 \pm 8.24$ \\
\hline & & $p=0.304$ & $p=0.087$ & $\mathrm{p}=0.182$ & $\mathrm{p}=0.177$ \\
\hline \multicolumn{6}{|l|}{ Age, years } \\
\hline $40-49$ & 170 & $7.61 \pm 0.80$ & $8.4 \pm 1.8$ & $6.04 \pm 2.60$ & $12.30 \pm 5.22$ \\
\hline $50-59$ & 252 & $7.97 \pm 0.86$ & $9.4 \pm 2.0$ & $7.52 \pm 3.43$ & $15.25 \pm 6.89$ \\
\hline $60-69$ & 135 & $8.21 \pm 0.89$ & $10.1 \pm 2.7$ & $8.91 \pm 7.73$ & $18.07 \pm 15.48$ \\
\hline$\geq 70$ & 26 & $8.33 \pm 0.83$ & $12.2 \pm 3.5$ & $12.88 \pm 8.54$ & $26.16 \pm 17.12$ \\
\hline \multicolumn{6}{|l|}{ SBP, mm Hg } \\
\hline$<100$ & 10 & $7.09 \pm 0.71$ & $7.8 \pm 2.2$ & $6.67 \pm 4.61$ & $13.58 \pm 9.32$ \\
\hline $100-109$ & 51 & $7.30 \pm 0.79$ & $8.4 \pm 1.9$ & $6.75 \pm 3.10$ & $13.71 \pm 6.22$ \\
\hline $110-119$ & 105 & $7.70 \pm 0.85$ & $8.9 \pm 2.8$ & $6.51 \pm 2.78$ & $13.23 \pm 5.59$ \\
\hline $120-129$ & 128 & $7.95 \pm 0.85$ & $9.2 \pm 2.1$ & $6.93 \pm 3.07$ & $14.07 \pm 6.22$ \\
\hline $130-139$ & 109 & $8.04 \pm 0.78$ & $9.6 \pm 2.5$ & $7.34 \pm 4.11$ & $14.9 \pm 8.24$ \\
\hline $140-149$ & 87 & $8.16 \pm 0.82$ & $9.5 \pm 2.0$ & $7.18 \pm 2.56$ & $14.58 \pm 5.15$ \\
\hline $150-159$ & 43 & $8.21 \pm 0.82$ & $10.0 \pm 2.2$ & $7.56 \pm 3.18$ & $13.35 \pm 6.36$ \\
\hline$\geq 160$ & 50 & $8.25 \pm 0.88$ & $10.5 \pm 2.4$ & $7.33 \pm 2.41$ & $14.9 \pm 4.85$ \\
\hline
\end{tabular}

Dd, diastolic diameter; PWV, pulse wave velocity; SBP, systolic blood pressure.

SBP increase by every $10 \mathrm{~mm} \mathrm{Hg}$ was associated with Dd increased by $0.15 \mathrm{~mm}$, PWV increased by $0.35 \mathrm{~m} / \mathrm{s}$, $\alpha$ increased by 0.13 and $\beta$ increased by 0.15 (table 2 , figure 5).

\section{DISCUSSION}

The Chinese CVD report of 2015 showed that the incidence of CVD is continuously increasing and will maintain an upward trend in the next decade in China. CVD was still the leading cause of death in $2014 .{ }^{10}$ The mortality of
CVD is significantly higher in China than in other developed countries. Both structural and functional changes of arteries have been a research focus for several years, as they are considered risk factors for cardiovascular events. ${ }^{11-13}$

Many studies showed that arterial stiffness is correlated with the presence and severity of arterial atherosclerosis and is also associated with myocardial dysfunction. ${ }^{14-16}$ Various risk factors such as hypertension, diabetes and metabolic syndrome (METS) cause the progression of

Table 3 Comparison between participants with and without hypertension by quality arterial stiffness (QAS) measurements after adjustment for age. Comparison between participants with and without diabetes by QAS after adjustment for age

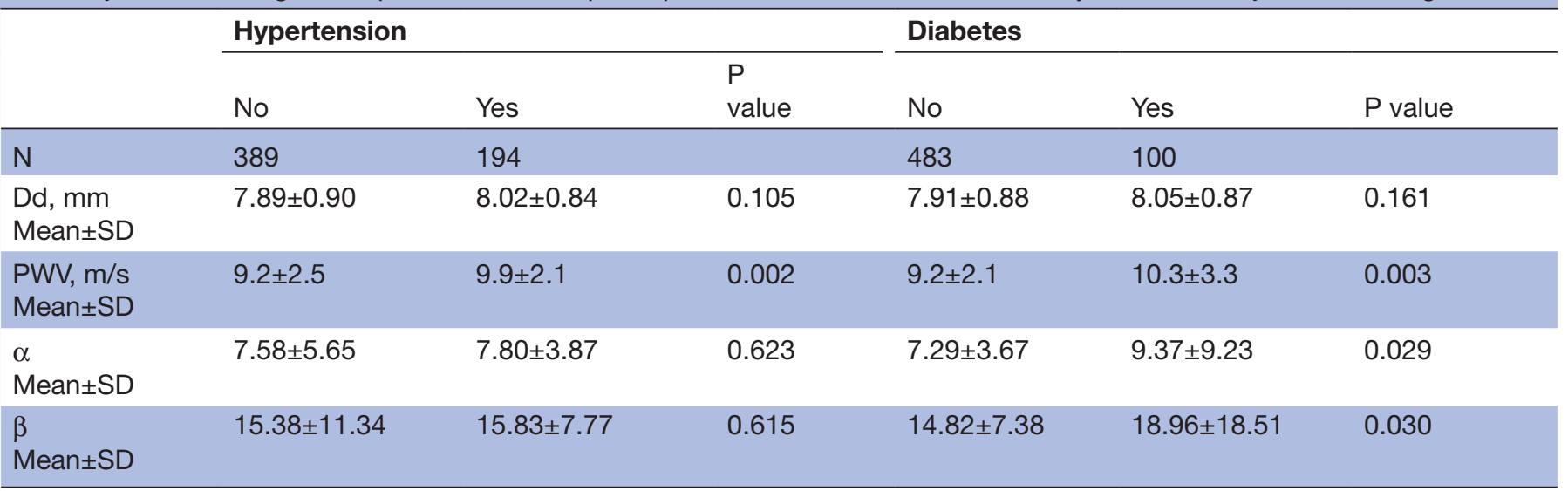

Dd, diastolic diameter; PWV, pulse wave velocity. 
Table 4 Comparison between participants in different risk levels of diabetes by Dd and PWV after adjustment for age

\begin{tabular}{|c|c|c|c|c|}
\hline & & $\mathbf{N}$ & $\begin{array}{l}\text { Dd, mm } \\
\text { Mean } \pm S D\end{array}$ & $\begin{array}{l}\mathrm{PWV}, \mathrm{m} / \mathrm{s} \\
\text { Mean } \pm \mathrm{SD}\end{array}$ \\
\hline All & & 583 & $7.93 \pm 0.88$ & $9.4 \pm 2.4$ \\
\hline \multirow[t]{3}{*}{$\begin{array}{l}\mathrm{HbA1c} \text {, } \\
\%\end{array}$} & $\begin{array}{l}\text { Lower risk } \\
\text { (participants } \\
\text { without } \\
\text { diabetes) } \\
<5.8\end{array}$ & 405 & $7.82 \pm 0.85$ & $9.2 \pm 2.1$ \\
\hline & $\begin{array}{l}\text { Increasing } \\
\text { risk of } \\
\text { diabetes } \\
\text { (participants } \\
\text { without } \\
\text { diabetes) } \\
5.8-6.4\end{array}$ & 78 & $8.06 \pm 0.84$ & $10.1 \pm 2.4$ \\
\hline & $\begin{array}{l}\text { Prior } \\
\text { diabetes or } \\
>6.4\end{array}$ & 100 & $8.58 \pm 0.88$ & $10.2 \pm 3.2$ \\
\hline
\end{tabular}

Dd, diastolic diameter; HbA1c, glycohemoglobin; PWV, pulse wave velocity.

arteriosclerosis. These factors may cause macrovascular and microvascular complications, leading to arterial wall thickening, endothelial dysfunction and calcification, finally resulting in arterial stiffness. Many studies showed that arterial stiffness is a strong predictor of future cardiovascular events. In addition, it is one of the earliest

All

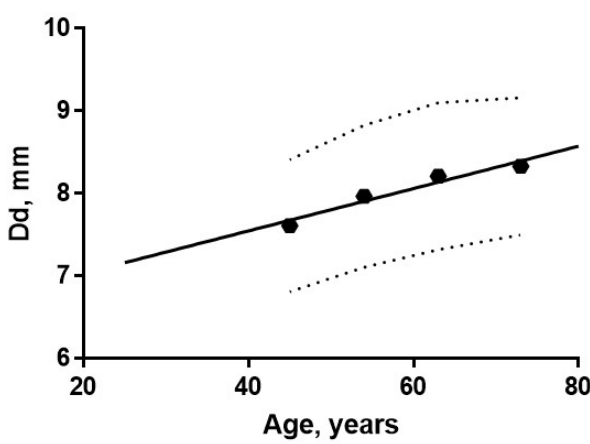

All

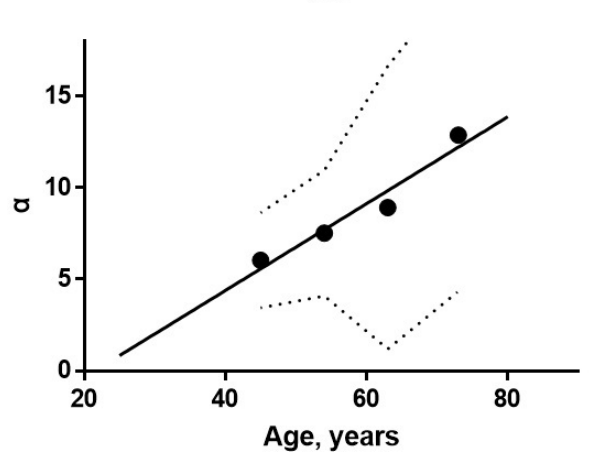

detectable manifestations of adverse structural and functional changes within the vessel wall. ${ }^{17} 18$ Both the Danish population study ${ }^{19}$ and Baltimore Longitudinal Study of Aging (BLSA) study ${ }^{20}$ have shown the predictive role of arterial stiffness for cardiovascular outcomes beyond traditional cardiovascular risk factors.

In our study, large population samples were collected. We focused on carotid wall changes by evaluating arterial stiffness using the ultrasound QAS technique, which is a rapid and specific manner to measure the stiffness parameters. For functional changes, we obtained the arterial stiffness parameters calculated by QAS, such as Dd, PWV, the stiffness indices $\alpha$ and $\beta$ to explore the baseline of the parameters. In our study, the value of Dd, PWV, $\alpha$ and $\beta$ increased with age (by approximately $0.27 \mathrm{~mm}, 1.2 \mathrm{~m} / \mathrm{s}$, 1.34 and 2.71, respectively, per 10-year increase in age); they also increased with SBP (by approximately $0.15 \mathrm{~mm}$, $0.35 \mathrm{~m} / \mathrm{s}, 0.13$ and 0.15 , respectively, for every $10 \mathrm{~mm} \mathrm{Hg}$ increase in SBP). According to the Chinese CVD report of 2015, hypertension and diabetes are two of the most common chronic non-infectious diseases and the most important risk factors for CVDs. As the most useful and robust index of arterial stiffness, ${ }^{21} \mathrm{PWV}$ measured by QAS likely provides accurate information regarding the local alterations in the vascular characteristics. In our study, we found that PWV provide some information related with hypertension and diabetes.

Arterial dysfunction is the pathophysiological change occurring in CVD. If we could identify the damage in arterial function early, it may be possible to intervene early
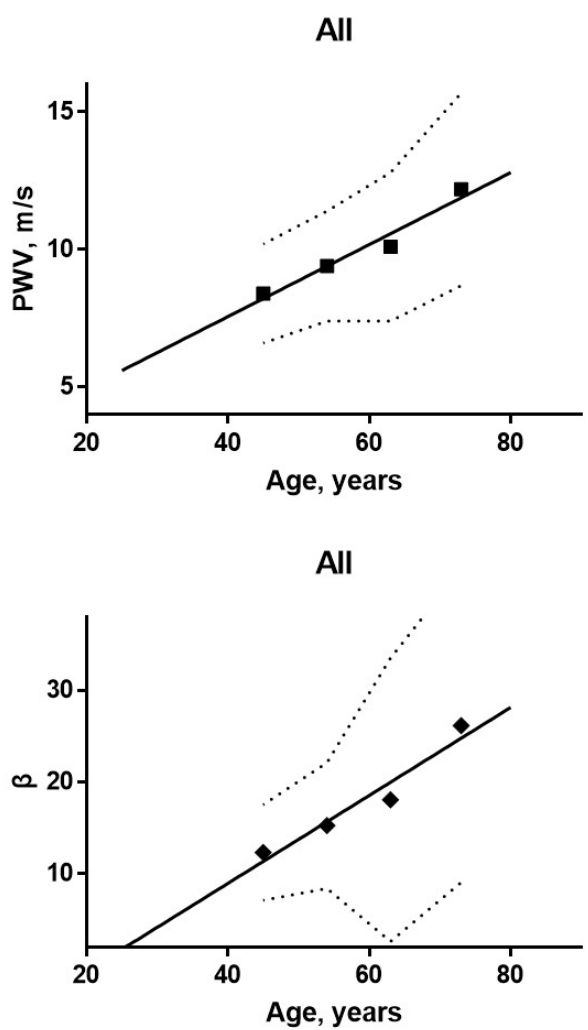

Figure 4 The increase in the mean Dd, PWV, $\alpha$ and $\beta$ with increasing age in the participants of the study. Dd, diastolic diameter; PWV, pulse wave velocity. 
All

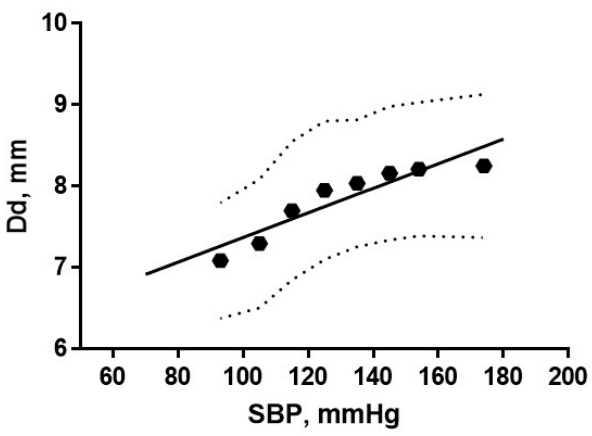

All

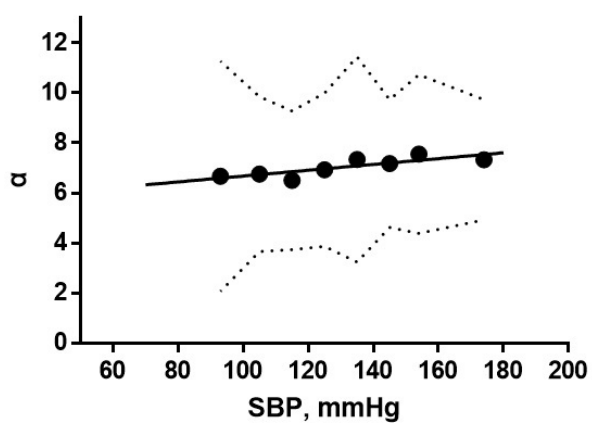

All

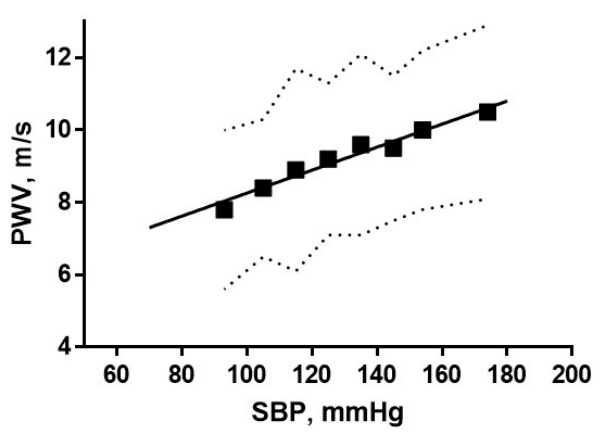

All

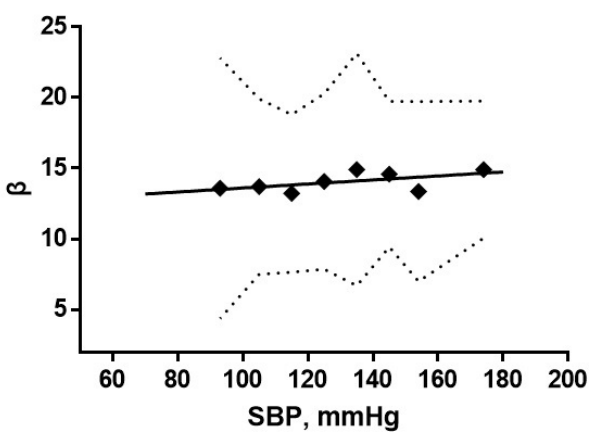

Figure 5 The increase in the mean Dd, PWV, $\alpha$ and $\beta$ with increasing SBP in the participants of the study. Dd, diastolic diameter; PWV, pulse wave velocity; SBP, systolic blood pressure.

before the occurrence of CVD events such as myocardial infarction. ${ }^{22}$ It is becoming clear that arterial stiffness may be increased even in pre-diabetic populations with impaired glucose tolerance and in those with METS well before the onset of overt diabetic mellitus (DM). A study with 91 patients demonstrated that patients with type 2 diabetes have significantly increased arterial stiffness as assessed by QAS. ${ }^{23}$ Our study also supported the conclusion. Some other data suggest that arterial stiffness can predict the DM. Arterial stiffness is irreversible in DM although HbAlc influenced by medical treatment in several patients. Several studies have shown that quantitative carotid stiffness as a functional index is influenced mainly by the quality of blood glucose control and a high-normal HbA1c level was independently associated with arterial stiffness, but not with carotid atherosclerotic parameters (such as intima-media thickness (IMT) and Dd), in the general population without diabetes. ${ }^{24-26}$ The functional atherosclerotic process may already be accelerated according to HbAlc level, even at a level below the diagnostic threshold for diabetes. There are many risk predictive models with great importance in primary practice. However, these models predicted the traditional risk factors instead of the vascular function itself due to a lack in recent vascular health assessment methods. In our study, the carotid arterial stiffness parameters Dd, PWV, $\alpha$ and $\beta$ we measured were much higher in the population with diabetes. Our study also showed the relationship between Dd, PWV and HbAlc. According to the HbAlc risk level mentioned before, in the lower risk of diabetes group, the value of PWV was significantly lower than the increasing risk of diabetes and presence of diabetes groups. These results validate the hypothesis that arterial remodelling occurring in local and elastic arteries increases the risk for future CVD, because the carotid artery can be considered as a model reflecting the conditions common to all involved arteries.

In our study, we focused on the population older than 40 years in the northern countryside of China. The healthcare development in rural areas is relatively backward compared with urban areas in China. People lived in rural areas usually neglect personal health management and have bad living habits such as smoking, high salt and high-carbonhydrate diet. All of these can cause a bad health condition leading to some severe chronic disease such CVD. The Chinese CVD report of 2015 also showed that CVD mortality in rural areas has exceeded that of urban areas since 2009. ${ }^{10}$ Thus, we make our efforts to explore some simple inspection methods which can be easily carried out in both rural and urban areas and find some new indicators such as non-invasive carotid arterial functional indices combined with traditional risk factors to comprehensively assess arterial structural and functional changes.

\section{Strengths and limitations of this study}

According to our study, the ultrasound automated QAS technique, which possesses favourable reliability and feasibility, can be used for assessing local arterial elasticity non-invasively and comprehensively. The technique can 
be used for large sample screening because it is economical and practical. However, the technique still has its limitations. QAS technique is based on RF technique. The RF signal tracked the vascular wall, while another signal tracked the motion of the vascular wall for at least six cardiac cycles and the mean and SD values were calculated automatically. In that case, anything that affects the cardiac cycle or vascular wall recognition will affect the measurement of QAS. The QAS data cannot be obtain satisfactorily in some conditions such as arrhythmia, carotid multiple atherosclerosis plaques, carotid with excessive bending, carotid with excessive pulsatility and excessive superficial carotid.

\section{CONCLUSION}

Arterial function evaluation is becoming more important than structural evaluation in recent studies. The ultrasound automated QAS technique, which possesses favourable reliability and feasibility, can be used for assessing local arterial elasticity non-invasively and comprehensively.

A total of 583 people in the northern countryside in China were enrolled into our present study at baseline. Stiffness of the carotid artery have differences between hypertension and non-hypertension adults, as well as between diabetes and non-diabetes adults. Stiffness of the carotid artery have differences between adults with $\mathrm{HbA1c}$ at $5.8 \%-6.4 \%$ versus $<5.8 \%$. Stiffness of the carotid artery increases with increasing age and increasing SBP at a range from 40 and up. The present study provides important information regarding the association between arterial function and the risk factors of CVD.

Acknowledgements Thanks are due to our colleagues who provided expertise that greatly assisted the research. Thanks are due to AJE website for assistance with editing for proper English language, grammar, punctuation, spelling and overall style.

Contributors YW: designed and conceptualised study; drafted and revised the manuscript; statistical analysis; interpreted the data; aquision of the data. MW: acquisition of the data. YG: acquisition of the data. XP: acquisition of the data. CS: acquisition of the data. XZ: acquisition of the data. FZ: acquisition of the data. YZ: obtained funding; supervised and coordinated study. LC: obtained funding; supervised and coordinated study. SZ: obtained funding; supervised and coordinated study. QD: supervised and coordinated study; designed and conceptualised study; revised the manuscript. MY: obtained funding; supervised and coordinated study; designed and conceptualised study; revised the manuscript; acquisition of the data.

Funding The work was supported by the Beijing Natural Science Foundation (JQ18023); National Natural Science Foundation of China (61971447, 81301268, 81671173); Beijing Nova Programme Interdisciplinary Cooperation Project (xxjc201812); International S\&T Cooperation Program of China (2015DFA30440); Beijing Nova Programme (Z131107000413063); PUMCH Science Fund for Junior Faculty (pumch-2016-1.6)

Competing interests None declared.

Patient consent for publication Not required.

Ethics approval The study was approved by the Ethical Committee at Peking Union Medical College Hospital (Reference number: B-160). All examinations were performed in accordance with relevant guidelines and regulations. Written informed consent was obtained from all participants.

Provenance and peer review Not commissioned; externally peer reviewed.
Open access This is an open access article distributed in accordance with the Creative Commons Attribution Non Commercial (CC BY-NC 4.0) license, which permits others to distribute, remix, adapt, build upon this work non-commercially, and license their derivative works on different terms, provided the original work is properly cited, appropriate credit is given, any changes made indicated, and the use is non-commercial. See: http://creativecommons.org/licenses/by-nc/4.0/.

ORCID iD

Yao Wei http://orcid.org/0000-0001-7011-5565

\section{REFERENCES}

1 Vlachopoulos C, Aznaouridis K, Stefanadis C. Prediction of cardiovascular events and all-cause mortality with arterial stiffness: a systematic review and meta-analysis. J Am Coll Cardiol 2010;55:1318-27.

2 Larsson M, Kremer F, Claus P, et al. Ultrasound-based radial and longitudinal strain estimation of the carotid artery: a feasibility study. IEEE Trans Ultrason Ferroelectr Freq Control 2011;58:2244-51.

3 Schmidt-Trucksäss A, Grathwohl D, Schmid A, et al. Structural, functional, and hemodynamic changes of the common carotid artery with age in male subjects. Arterioscler Thromb Vasc Biol 1999;19:1091-7.

4 Schöning M, Walter J, Scheel P. Estimation of cerebral blood flow through color duplex sonography of the carotid and vertebral arteries in healthy adults. Stroke 1994;25:17-22.

5 Hoeks AP, Willekes C, Boutouyrie P, et al. Automated detection of local artery wall thickness based on M-line signal processing. Ultrasound Med Biol 1997;23:1017-23.

6 Zhai F-F, Yan S, Li M-L, et al. Intracranial arterial dolichoectasia and stenosis: risk factors and relation to cerebral small vessel disease. Stroke 2018;49:1135-40.

7 Wang L, Yang M, Su N, et al. Ultrasound radiofrequency-data technique assessment of carotid: a reproducibility study. Chin $J$ Ultrasonogr 2014;23:484-8.

8 Bramwell JC, Hill AV. The velocity of pulse wave in man.Proceedings of the Royal Society of London. , 1922: 93, 298-306.

9 American Diabetes Association. Standards of medical care in diabetes--2011. Diabetes Care 2011;34 Suppl 1:S11-61.

10 Chen W-W, Gao R-L, Liu L-S, et al. China cardiovascular diseases report 2015: a summary. J Geriatr Cardiol 2017;14:1-10.

11 Kearney-Schwartz A, Rossignol P, Bracard S, et al. Vascular structure and function is correlated to cognitive performance and white matter hyperintensities in older hypertensive patients with subjective memory complaints. Stroke 2009;40:1229-36.

12 Halcox JPJ, Donald AE, Ellins E, et al. Endothelial function predicts progression of carotid intima-media thickness. Circulation 2009;119:1005-12.

13 Barra S, Gaeta G, Cuomo S, et al. Early increase of carotid intimamedia thickness in children with parental history of premature myocardial infarction. Heart 2009;95:642-5.

14 Myung Y, Seo H-S, Jung IH, et al. The correlation of carotid artery stiffness with heart function in hypertensive patients. $J$ Cardiovasc Ultrasound 2012;20:134-9.

15 Yiu K-H, Zhao C-T, Chen Y, et al. Association of subclinical myocardial injury with arterial stiffness in patients with type 2 diabetes mellitus. Cardiovasc Diabetol 2013;12:94.

16 Yang EY, Chambless L, Sharrett AR, et al. Carotid arterial wall characteristics are associated with incident ischemic stroke but not coronary heart disease in the Atherosclerosis risk in communities (ARIC) study. Stroke 2012;43:103-8.

17 Cavalcante JL, Lima JAC, Redheuil A, et al. Aortic stiffness: current understanding and future directions. J Am Coll Cardiol 2011;57:1511-22.

18 McEniery CM, Wilkinson IB, Avolio AP. Age, hypertension and arterial function. Clin Exp Pharmacol Physiol 2007;34:665-71.

19 Willum-Hansen T, Staessen JA, Torp-Pedersen C, et al. Prognostic value of aortic pulse wave velocity as index of arterial stiffness in the general population. Circulation 2006;113:664-70.

20 Najjar SS, Scuteri A, Shetty V, et al. Pulse wave velocity is an independent predictor of the longitudinal increase in systolic blood pressure and of incident hypertension in the Baltimore longitudinal study of aging. J Am Coll Cardiol 2008;51:1377-83.

21 Rossi P, Francès Y, Kingwell BA, et al. Gender differences in artery wall biomechanical properties throughout life. $J$ Hypertens 2011;29:1023-33.

$22 \mathrm{Liu} \mathrm{H}$, Liu J, Zhao H, et al. The design and rationale of the Beijing vascular disease patients evaluation study (best study). Contemp Clin Trials Commun 2017;7:18-22. 
23 Zhang L, Yin J-K, Duan Y-Y, et al. Evaluation of carotid artery elasticity changes in patients with type 2 diabetes. Cardiovasc Diabetol 2014;13:39

24 Liu Y-P, Zhan W-W, Zhang Y-F, et al. Carotid intima-media thickness and stiffness in relation to type 2 diabetes in Chinese. Endocrine 2007;31:289-93.
25 Lee Y-H, Shin M-H, Choi J-S, et al. Hba1C is significantly associated with arterial stiffness but not with carotid atherosclerosis in a community-based population without type 2 diabetes: the Dong-gu study. Atherosclerosis 2016;247:1-6.

26 Prenner SB, Chirinos JA. Arterial stiffness in diabetes mellitus. Atherosclerosis 2015;238:370-9. 